\title{
Relevancia del destete prematuro como factor causal de desnutrición y mortalidad infantil en Chile 1974
}

DRA. PATRIOIA MARIN $\mathrm{s}$, *.

En Chile mueren anualmente 19.752 niños menores de 1 año, lo que corresponde a una tasa de $71,1 \%$ n.v. (SNS 1972). Es decir, es uno de los 10 países latinoamericanos con tasas de mortalidad infantil más altas del Continente. Por otro lado y paradojalmente, es el país latinoamericano que da la mayor atención en el cuidado prenatal. También es el país que proporciona más vacunas antisarampión, antidifteria y antipolio, lo que se tradujo, en 1973, por ejemplo, en una muy baja tasa de mortalidad infantil por estas tres causas (1). Todos estos antecedentes nos hacen concluir que a pesar de la muy adecuada atención médica tanto de la madre y del niño, sigue persistiendo una elevada tasa de mortalidad infantil (2).

La tasa de mortalidad infantil es uno de los indicadores usados internacionalmente para comparar el grado de desarrollo de un país, y no sólo mide esto, sino que, además, sirve para evaluar efectividad de programas nacionales, y en consecuencia, de gobiernos.

Las estadísticas nacionales existentes sobre lactancia materna indican que sólo el $60 \%$ de las madres comienza poniendo el pecho a sus hijos al nacer; y de éstas sólo un $30 \%$ llegan al tercer mes de vida. La protección conferida por la leche materna contra las infecciones ha sido objeto de numerosos estudios y el tema fue examinado recientemente por Malta y Wyatt (1971). Al parecer es de opinión unánime que la alimentación al seno, comparada con otras fuentes de nutrientes rebaja las tasas de ataque por enfermedades infecciosas, especialmente diarreas y bronconeumonías. Si lográramos una lactancia prolongada hasta el $6^{\circ}$ mes de \footnotetext{
* Departamento de Pediatría. Hospital L. Calvo Mackenna.
Santiago - Chile.
}

vida, la tasa de mortalidad infantil por diarreas caería en 10.6 (SNS 1972) (5), es decir, quedaríamos con una tasa 60.5; como también la lactancia natural disminuye la incidencia de bronconeumonias, la reducción total sería de 31.7 , es decir, la tasa de mortalidad infantil caería de 71.1 a 39.4 , cifra ya muy cercana a la de países latinoamericanos que han logrado salir del subdesarrollo.

De todos los niños menores de un año que mueren anualmente en Chile 8.942 mueren por diarreas y bronconeumonías (SNS 1972), y de éstos más del 60\% mueren antes de los seis meses de vida (3).

\section{Quiénes mueren por diarreas y qué sucede con las diarreas.}

En Chile es una de las causas más frecuentes de muerte del menor de 1 año y principalmente del menor de 6 meses. Estadísticas recientes indican que gran cantidad de los niños nacidos vivos mueren por diarrea antes de los 6 meses, y un porcentaje menor entre 6 meses y 1 año (4). Es obvio que el grupo de niños menores es el más vulnerable. Ahora bien, si pensamos en la ecología de las diarreas donde participan agentes (microbios), huésped (niño) y ambiente, vemos que el huésped es totalmente dependiente de la mano que lo alimenta y que su nutrición es a base de leche, la que es un excelente medio de cultivo de gérmenes. Los ingleses definen la epidemiología de las diarreas diciendo que "es una mano (madre) que lleva gérmenes a una boca" (hijo). En cuanto al ambiente, la manipulación depende de factores de nivel de vida, es decir provisión de agua, eliminación de 
excretas, hábitos higiénicos, nivel cultural, etc. Todo ello muy difícil de mejorar y que requeriría bastante tiempo. Todo ello se evita con leche natural, el huésped recibe la mejor alimentación y el ambiente queda supeditado sólo al aseo del pezón materno, lo que es mucho más fácil y rápido de aprender por parte de la madre.

\section{Relevancia de la lactancia materna en nutrición.}

Infecciones y desnutrición van siempre juntas y se potencian bidireccionalmente.

El marasmo nutricional se presenta en Chile principalmente en el menor de 6 meses (6) y entre los fallecidos un $70 \%$ presenta un déficit nutricional.

La leche materna, a través de los mecanismos protectores contra la infección (entre los que la buena nutrición constituye uno de los importantes ), favorece un balance positivo de nutrientes y por lo tanto de crecimiento y desarrollo normales.

El déficit nutricional como causa básica o asociada de muerte de niños entre 28 días y 5 meses, es mucho menos frecuente en Chile entre los niños amamantados que nunca fueron destetados que en los que no recibieron leche materna o la recibieron durante períodos muy limitados.

\section{$\%$ de niños que murieron con déficit nutricional (1972)}

$15 \%$ amamantados nunca destetados $35 \%$ amamantados menos de 1 mes $50 \%$ no amamantados.
Esto nos indica que hay una elevada proporción de defunciones por enfermedad diarreica y déficit nutricional entre niños que no recibieron leche materna o la recibieron en medida muy limitada.

Para reducir la mortalidad y proteger la salud de los sobrevivientes es preciso proporcionar alimentos adecuados y el alimento más adecuado en el menor de 6 meses, es sin duda la leche materna.

En los programas educativos llevados a cabo por personal de la salud, se debería insistir especialmente en la importancia de la leche materna para la salud del niño. Las actividades a nivel de la comunidad encaminadas a fomentar la alimentación al seno, con la participación activa de grupos organizados y de las autoridades de salud, constituyen una necesidad urgente en Chile.

\section{REFERENCIAS}

1.- Control de la desnutrición en los niños, Ruth Puffer, pág. 15, libro resumen.

2.- Características de la mortalidad en los niños Ruth Rice Puffer.

3.- Ruth Puffer, pág. 25.

4.- Ruth Puffer, pág. 13.

5.- La tasa de mortalidad infantil por diarreas en Chile es 10.6 lo que equivale a 2.997 muertos por esta causa en 1 año.

La tasa de mortalidad infantil por bronconeumonia es de 21.1 es decir 5.945 muertos por esta causa (SNS 1972).

6.- Ruth Puffer, pág. 17. 